\title{
Cartografías en torno a los tránsitos en el aprender de docentes en educación infantil y primaria
}

\section{Mapping Infant and Primary Education Teachers' Transits When Learning}

\author{
Aingeru Gutiérrez-Cabello Barragán ${ }^{1}$ \\ aingeru.gutierrez-cabello@ehu.eus \\ Estibaliz Aberasturi-Apraiz \\ estitxu.aberasturi@ehu.eus \\ Universidad del País Vasco UPV/EHU, España
}

\section{Resumen:}

El aprendizaje del profesorado continúa siendo pensado bajo causalidades simples y en términos lineales. Sin embargo, el contexto de incertidumbre y diversidad actual al que deben hacer frente las maestras en sus escuelas nos invita a tener que desarrollar una conceptualización mucho más compleja de su aprendizaje. Mediante un abordaje de investigación basado en metodologías artísticas y visuales hemos intentado profundizar sobre la experiencia de aprendizaje de las maestras de educación primaria e infantil. Bajo una perspectiva de investigación que ubicamos dentro de los nuevos materialismos, abordamos una temática de estudio que requiere ser explorada bajo enfoques más holísticos y problematizadores. Nuestra aproximación a las experiencias de las maestras nos ha permitido pensar acerca de tres tránsitos en las formas en que se desarrolla su aprendizaje en la actualidad, vinculados a su agencia,

\begin{abstract}
:
Teacher learning continues to be thought under simple causalities and in linear terms. However, the current context of uncertainty and diversity which teachers must face in their schools encouraged us to develop a much more complex conceptualization of their learning. Through a research approach based on artistic and visual methodologies, we tried to deepen the learning experience of primary and infant education teachers. From a research perspective that we located within new materialism, we looked at teacher learning from more holistic and problematizing approaches. Our approximation to the experiences of teachers allowed us to identify three transits regarding how their learning takes place. Such transits are related to teachers' agency, the role of the experiential and new ways of selforganization.
\end{abstract}

1 Dirección para correspondencia (correspondence address):

Aingeru Gutiérrez-Cabello Barragán. Universidad del País Vasco UPV/EHU. Departamento de Didáctica y Organización Escolar. Facultad de Educación y Deporte. C/ Juan Ibáñez de Sto. Domingo 1. 01006 - Vitoria-Gasteiz (España). 
Cartografías en torno a los tránsitos en el aprender de docentes en educación infantil y primaria

Aingeru Gutiérrez-Cabello Barragán y Estibaliz Aberasturi-Apraiz

el papel de lo experiencial y las nuevas formas de auto-organización.

\section{Palabras clave:}

Aprendizaje del profesorado; conocimiento profesional; métodos artísticos; investigación post-cualitativa; nuevos materialismos.

\section{Key words:}

Teachers' learning; professional knowledge; artistic methods; post-qualitative research; new materialism.

\section{Résumé:}

L'apprentissage des enseignants continue à être pensé sous de simples causalités et en termes linéaires. Cependant, le contexte actuel $\mathrm{d}^{\prime}$ incertitude et de diversité auquel les enseignants sont confrontés dans leurs écoles nous invite à développer une conceptualisation beaucoup plus complexe de leurs apprentissages. Grâce à une approche de recherche basée sur des méthodologies artistiques et visuelles, nous avons essayé d'approfondir l'expérience de l'apprentissage des enseignants du primaire et l'éducation des enfants. Dans une perspective de recherche que nous situons dans les nouveaux matérialismes, nous abordons un sujet d'étude qui doit être exploré dans le cadre d'approches plus globales et problématisantes. Notre approche des expériences des enseignants nous a permis de réfléchir à trois transits sur la manière dont leur apprentissage est actuellement développé, liés à leur agence, au rôle de l'expérience et aux nouvelles formes d'autoorganisation.

\section{Mots clés:}

Apprentissage de I'enseignant; connaissances professionnelles méthodes artistiques; recherche post-qualitative; nouveaux matérialismes.

Fecha de recepción: 22-11-2018

Fecha de aceptación: 22-2-2019

\section{Introducción}

Desde la Facultad de Educación donde venimos desarrollando nuestra labor docente e investigadora, nos parecía esencial seguir profundizando sobre las muchas formas que adopta actualmente el aprendizaje del profesorado a la luz de los cambios sociales, culturales, económicos y digitales que vienen produciéndose. Esta realidad cada vez más compleja e incierta nos interpela a pensar acerca de los retos que deben hacer frente las maestras para poder ejercer su labor en contextos progresivamente más diversos, desiguales y caracterizados por la precariedad laboral. El marco donde se desarrolla actualmente la enseñanza hizo cuestionarnos acerca de las perspectivas que han concebido el aprendizaje del profesorado en términos lineales, sencillos y poco problematizadores. Movidos por nuestra propia experiencia acumulada durante 
más de veinte años dentro de la formación del profesorado, así como el reducido número de investigaciones (Borko, 2004; Opfer y Pedder, 2011; Wenger-Trayner, Fenton-O'Creevy, Kubiak, Hutchinson, y WengerTrayner, 2014) que habían profundizado sobre la complejidad que encierra el aprendizaje docente, decidimos embarcarnos en un proyecto que nos permitiera continuar añadiendo más texturas a la comprensión de una realidad -el aprendizaje docente- poco explorada aún y en continua transformación.

\section{El proyecto APREN-DO}

Durante el año 2015 desde los grupos de investigación Elkarrikertuz (IT887-16) de la Universidad del País Vasco (UPV/EHU) y el grupo Esbrina (2017 SGR 1248) de la Universidad de Barcelona (UB) nos plateamos el reto de profundizar sobre el aprendizaje del profesorado en el proyecto APREN-DO: Cómo aprenden los docentes: Implicaciones educativas y retos para afrontar el cambio social (EDU2015-70912-C2-1-R). La pregunta inicial, centrada básicamente en explorar el aprender del profesorado, nos movilizaba a ambos grupos en una misma dirección. No obstante, mientras que nuestro grupo en el País Vasco colaboraba con maestras de las etapas de Educación Infantil y Primaria en el desarrollo de este estudio, el grupo Esbrina trabajó junto a profesorado de Educación Secundaria.

Durante este proyecto nos plateamos la necesidad de desplegar una conceptualización amplia y compleja sobre el aprendizaje docente. Algo que nos llevase a tener que tomar en consideración su aprendizaje de una forma holística, bajo la diversidad de sistemas donde puede llegar a desarrollarse. Tanto en aquellas situaciones de aprendizaje que suceden dentro de su realidad profesional, como en las que se originan fuera de ella. Por ello, durante la investigación, centramos nuestra atención sobre los contextos situados donde se despliega realmente su aprender. Observando la realidad de su práctica en las aulas, dentro de las comunidades a las que pertenecen, o incluso en las redes sociales y culturales que construyen para satisfacer sus necesidades de formación y crecimiento individual. Se trataba en definitiva de prestar atención a los distintos espacios por donde transita el profesorado y los cambios que acompañan a sus prácticas, creencias e identidades mientras participan de ellos. 
Intentar abarcar y conducir la complejidad de este proyecto implicaba tener que plantearnos algunas preguntas, tales como, ¿Qué aporta la bibliografía (investigaciones e informes) sobre cómo el profesorado aprende?, ¿Cómo aprende el profesorado en contextos profesionales y cotidianos?, ¿Cómo transitan e interactúan estos modos de aprender?, ¿Cuál es el papel de los otros en estas experiencias de aprendizaje?, ¿Qué papel representan las cada vez más omnipresentes tecnologías digitales?, ¿Qué influye en el aprendizaje docente?, ¿Cómo representar los sistemas que reflejan la complejidad del aprendizaje docente?, ¿Qué aportan los métodos artísticos combinados con otros métodos cualitativos para dar cuenta de la experiencia de cómo los docentes aprenden?, ¿Cómo la investigación sobre las experiencias de aprender de los docentes pueden contribuir a afrontar los retos que hoy tiene planteada la formación del profesorado y las demandas de cambio de la educación para afrontar los retos de la sociedad contemporánea?.

La dificultad de los planteamientos nos hizo tener que desplazar nuestras formas tradicionales de aproximarnos a la realidad del profesorado. Por ello, durante esta investigación decidimos basarnos en las posibilidades que nos ofrecían los métodos artísticos y visuales para así dar cuenta de la experiencia de aprendizaje de los docentes. Por su capacidad para generar nuevos diálogos y narraciones de forma participativa en torno al tema que trajimos a explorar, pensamos que adoptar métodos de investigación basados en las artes nos permitiría desvelar nuevos matices aún ocultos en torno a los modos de aprender del profesorado. En esencia, suponía tener que asumir un planteamiento en la investigación no solamente capaz de permitirnos producir un tipo de conocimiento distinto, sino también una forma diferente de producir conocimiento (St. Pierre, 1997). Un nuevo posicionamiento que nos haría tener que alejarnos de los convencionalismos que guardan las aproximaciones humanistas de la investigación cualitativa, haciéndonos asumir una forma alternativa de afrontar nuestra tarea. Y a su vez, teniendo que replantearnos, el lugar que han venido ocupando la teoría, los participantes, los datos o la propia escritura en nuestras investigaciones previas. 


\section{Adoptar posiciones desde los nuevos materialismos en la investigación}

Aproximarnos al horizonte teórico que ofrecen los denominados post- o nuevos materialismos (Coole y Frost, 2010) nos ha permitido ampliar la visión humanista tan generalizada dentro de las perspectivas de investigación en las actuales ciencias sociales; más aún, cuando el sujeto que se prefigura siempre se realiza desde una posición muy concreta (hombre, blanco, occidental, heterosexual, etc.) para después pasar a generalizarse como referente universal y normativo. El adjetivo de "nuevo" que adquiere esta perspectiva de investigación, no enuncia necesariamente que sea tal cosa, sino que más bien supone una invitación a intentar pensar de manera distinta a como lo venimos haciendo. Una cuestión que se hace más necesaria que nunca, debido entre otras cosas, a que el mundo en el que vivimos ya no puede ser explicado o justificado a través de un pensamiento ortodoxo (St. Pierre, Jackson, y Mazzei, 2016).

Los nuevos materialismos tal y como apunta Hird (2004), nos han llevado a concebir la materia como un complejo sistema sujeto a propiedades emergentes. El giro hacia la materia que se refleja en la ontología propia de los nuevos materialismos emerge a raíz de su preocupación por los procesos de producción social, las capacidades de la materia y las formas en que interacciona. Rosi Braidotti (2006) sugiere que los nuevos materialismos emergen como un método, como un marco conceptual y un posicionamiento político que reúsa el paradigma del lenguaje, y subraya la complejidad material de los cuerpos inmersos en relaciones de poder dentro del ámbito social (Dolphijn y van der Tuin, 2012).

Los nuevos materialismos parten de una noción de 'agencia' desvinculada de la acción humana individual, centrando su foco de interés en las redes o ensamblajes de lo humano y no humano, de lo animado e inanimado, lo material y lo abstracto (Fox y Alldred, 2015). El descentramiento del sujeto como origen de todas las acciones ha supuesto configurar una nueva red de influencias más amplia e indeterminada, como en el materialismo vibrante de Jane Bennett (2010) o el de los animismos contemporáneos (Harvey, 2014). Nuestras vidas se encuentran inevitablemente condicionadas bajo la constante influencia de elementos no humanos (lo tecnológico, digital o animal, al menos), una cuestión que nos plantea hablar incluso de nuestra naturaleza cyborg (Haraway, 1991b). Una condición híbrida y unas relaciones organismo-máquina 
que hacen cuestionarnos nuestra esencia unitaria y naturalizada por nuestra propia cultura occidental.

Desde el enfoque de los nuevos materialismos existe un intento por hacer hincapié en la materia, pero desde una visión monista que escape de los dualismos del tipo estructura/agencia o materia/lenguaje (Dolphijn y van der Tuin, 2012). Las distintas materialidades (cuerpos, objetos, órganos, especies, lenguaje, etc.) no suponen ser elementos ontológicamente superiores unos a otros, sino que más bien ocupan un determinado lugar dentro de una relación de contingencia con respecto a otras materias o ideas (Haraway, 1991a). El pensamiento de los distintos autores implicados en los nuevos materialismos (Barad, 1996; Braidotti, 2006; De Landa, 2006b) se preocupan por las asociaciones que establecen las distintas materias entre sí y por las consecuencias que derivan de dichas interacciones; en definitiva, por su capacidad para afectar y verse afectadas, utilizando una aproximación spinozista de la noción de afecto (Deleuze y Guattari, 2004). De hecho, son las investigaciones más recientes en ciencias sociales las que demuestran la inseparabilidad de lo simbólico y lo material en el examen de la construcción discursiva de los objetos de conocimiento, y en sus efectos materiales (Sheridan, 2002).

Los nuevos materialismos critican la atención que desde las corrientes post-estructuralistas se ha prestado a la agencia del lenguaje y la construcción discursiva de la realidad (van der Tuin y Dolphijn, 2010). Se trata más bien, tal y como propone la autora Karen Barad (2003), de asumir una comprensión performativa de la realidad que deje de prestar atención a las representaciones lingüísticas en favor de las prácticas discursivas. Los nuevos materialismos problematizan la orientación que llevan a cabo las corrientes constructivistas en sus análisis, en el sentido de mostrarse inadecuadas para pensar sobre el papel de la materia, la materialidad y la política en el actual contexto de decisiones bio-políticas y economía global (Coole y Frost, 2010). Los análisis neo-materialistas disuelven así los límites entre lo que tradicionalmente ha sido asignado a los niveles "macro" de las instituciones y de la organización social, y el nivel "micro" de la experiencia y deseos humanos; asumiendo además la capacidad innata para afectar o verse afectados de todos estos aspectos de lo social (Fox, 2015).

Las perspectivas de pensamiento que encierran los nuevos materialismos asumen posturas teórico-metodológicas diversas como puedan ser la teoría del actor-red de Bruno Latour (2005), la aproximación de Manuel De Landa (2006b) a partir de una teoría de los ensamblajes, pa- 
sando por el materialismo vital de Jane Bennett (2010); el materialismo feminista y anti-humanista de Elizabeth Grosz (2010) o la perspectiva nómada que adopta Rosi Braidotti (2000). Todas ellas suponen propuestas teóricas ambiciosas y coherentes con los tiempos contemporáneos, pero también comprometidas en explorar la capacidad de agencia de los distintos actores, tanto humanos como no humanos, así como las formas de relación desigual en la manera en que se constituyen mutuamente.

Las nuevas teorías materialistas, al menos aquellas que optan por desarrollarse desde posiciones problematizadoras de la realidad, se plantean preguntas sobre el acontecer de determinadas inercias sociales o educativas a pesar de las tentativas que se realizan para su transformación. Dicho de otra manera, lo que proponen estos enfoques es qué clase de fuerzas hacen perseverar determinadas dinámicas a pesar del intento explícito por ser transformadas. Los nuevos materialismos realizan un intento por explorar las ontologías existentes en nuestras realidades; sobre las agencias de las distintas materias y el lugar donde se ubican, e incluso sobre la conflictividad, descontrol o cambio al que derivan determinados ensamblajes. Los denominados nuevos materialismos, nos permiten pensar no solamente acerca de las relaciones de poder que se establecen en determinados espacios, sino también sobre la influencia que ejercen los objetos, las infraestructuras, las materias, las tecnologías, el lenguaje, etc., en la construcción de situaciones de injusticia y desigualdad.

Precisamente desde esa interpretación crítica que realizan determinados enfoques materialistas contemporáneos, nos hemos planteado que durante este trabajo sería interesante profundizar al menos sobre las siguientes dos cuestiones. La primera de ellas alude a nuestro deseo por explorar cómo se encuentran influyendo en el aprendizaje de las maestras participantes en nuestra investigación, las diversas fuerzas materiales, siempre múltiples, no lineales, afectivas y relacionales por las que se hallan envueltas. Una cuestión que supone aproximarse hacia aquellos ensamblajes de fuerzas, frecuentemente invisibilizados o que pasan simplemente desapercibidos dentro de la realidad del aprendizaje del profesorado. Este propósito nos invita a tener que considerar la manera en que se constituyen los discursos, así como la materialidad y la corporeidad dentro de los marcos de relación y políticos de nuestra realidad presente y sus influencias sobre la construcción de la subjetividad de las maestras; porque tal y como apuntan Coole y Frost (2010), las subjetividades pueden ser entendidas como aquellas series de capacidades o potencias 
que de forma azarosa y ambigua emergen de una multitud de procesos orgánicos y sociales.

Por otro lado, en este trabajo hemos partido del cuestionamiento que realizan los nuevos materialismos sobre la idea ilustrada que entendía la soberanía individual como un derecho preestablecido que constituía al propio sujeto (Grosz, 2010) y que suponía a su vez, una interpretación unificada de la subjetividad de los individuos (McLaren, 2002). Por ello, nos plateamos indagar acerca de la forma en que las maestras negocian sus subjetividades movidas por un nomadismo (Braidotti, 2000) capaz de transcender los determinismos de una realidad profesional excesivamente polarizada. Parece importante considerar la manera en que las maestras se constituyen en la intra-acción con la materialidad de sus contextos y cómo les lleva a desarrollar una relación dialéctica entre sus múltiples subjetividades condicionadas bajo la red de fuerzas en la relación. El tipo de pensamiento que hacen emerger los nuevos materialismos permite construir nuevas maneras de pensar acerca de la subjetividad, desestabilizando los limites de la imaginación. A este respecto, nos sumamos a la posibilidad que plantea Haraway (1991a) de poder desarrollar una objetividad encarnada que contribuya a reconocer la realidad de las experiencias personales y de su permeabilidad al poder.

\section{Cartografía de un aprendizaje}

A lo largo de este estudio invitamos a veintidós maestras -once de educación infantil y once de educación primaria- a que tomaran parte en la experiencia. El contacto inicial lo realizamos a través de una carta donde les expusimos el propósito de la investigación y les planteamos participar en una primera sesión presencial que nos permitiera pensar conjuntamente sobre el lugar que ocupa el aprendizaje en sus vidas. Para esa primera reunión se les instó a traer al menos cinco imágenes que mostrasen la manera en que aprenden actualmente, tanto dentro como fuera de los límites formales de la escuela. El trabajo exploratorio realizado durante esa jornada nos permitió analizar la propia experiencia de aprender a partir de distintos elementos visuales -fotografías, imágenes, objetos, etc.- vinculados a su historia personal. Todo ello bajo el objetivo de comenzar a construir evidencias que ayudasen trazar sus tránsitos dentro y fuera del espacio escolar y dialogar a partir de ellos. 


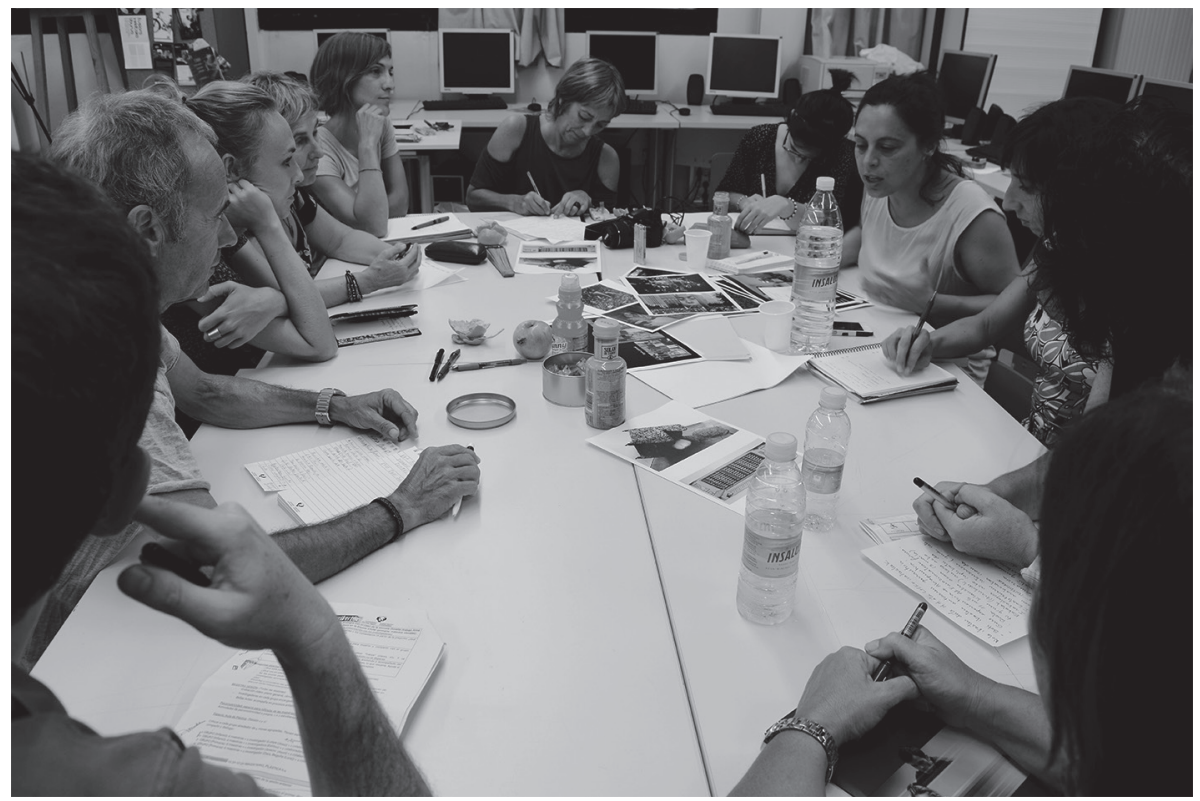

Figura 1. Primera sesión de trabajo con las maestras donde conversamos a partir de las imágenes seleccionadas sobre sus experiencias de aprendizaje.

La segunda de las sesiones se desarrolló con la intención de buscar las conexiones, en la mayoría de las ocasiones invisibles, que guardaban aquellas imágenes, conceptos u otros elementos que trajeron. Para ello necesitábamos construir una herramienta, un dispositivo capaz de llevarnos a dialogar sobre la forma en que se relacionan las distintas experiencias que conforman el aprender de las maestras; un medio para explorar una realidad demasiado compleja para ser categorizada en rígidos sistemas cerrados. Se trataba de construir una suerte de máquina de subjetivización disruptiva que nos permitiera desarrollar otras formas de interpretar las propias experiencias del aprender por las que transitamos. Así, a partir de la profundidad y extensión con la que Deleuze y Guattari (2004) desarrollaron una aproximación geo-filosófica a la realidad, decidimos valernos de su herramienta cartográfica como un medio para seguir profundizando en las distintas realidades del aprender docente. Lo cartográfico en nuestra investigación adquiría el sentido de una producción plástica donde poder ensamblar tantos elementos visuales como se considerasen necesarios para hablar sobre la manera en cómo aprendemos. Una base de cartón, papel o cartulina conformaba el territorio 
donde ir elaborando el relato visual que sirviera para conectar imágenes, insertar ideas o mapear deseos que hablasen sobre el aprender.

Para Deleuze (1996) lo cartográfico estaría relacionado con el mapa, con el diagrama que permite trazar una composición de los mecanismos de poder. Pero a su vez, lo cartográfico, también haría referencia a un sistema no representacional de los procesos de subjetivación, siempre desmontables, reversibles, susceptibles a constantes modificaciones (Deleuze y Guattari, 2004). Una máquina abstracta que nos abriría a la posibilidad de poder crear nuestras propias líneas de fuga con las que hacer frente a las relaciones de fuerzas que nos constituyen. A partir de esta doble vía interpretativa, comenzamos a desarrollar nuestra tarea investigadora. Abriéndonos a explorar tal y como sugiere Rosi Braidotti (2018) en el uso de lo cartográfico, el tipo de sujetos de saber que somos en el proceso de devenir, así como la clase de discursos por los que nos vemos afectados. Algo que suponía establecer relaciones con la diversidad de ficciones que aún dan forma a nuestras identidades escolarizadas (Achilli, 1996), mientras también dialogábamos de otras muchas cuestiones frecuentemente invisibilizadas, naturalizadas en los procesos de formación docente.

Tomar la decisión de adoptar métodos de investigación basados en las artes, mediante la utilización de procesos cartográficos nos llevó a tener que repensar el tipo de evidencias que pasarían a formar parte de este trabajo. La apertura a generar otras formas de construir los datos nos hacía asumir, además, sus posibles orígenes diversos, asumiendo que no solamente pueden surgir de las transcripciones, observaciones o notas de campo, sino también de los propios sueños, en el cuerpo, o la memoria (St. Pierre, 2017) del investigador. Las evidencias generadas a partir de las sesiones de trabajo con las maestras participantes, nos permitió construir toda una suerte de evidencias de investigación, un tipo de "transgressive data" al que apunta St. Pierre (2011b), que transcendía lo escrito como único medio para poder construir significados en torno al objeto de estudio. Esta otra clase de evidencias, nos ofrecían la oportunidad de abrirnos a un tipo de diálogo quizá más de tipo emocional o incluso sensual (St. Pierre, 1997) con los datos, haciéndonos más sensibles a construir otras formas distintas de conocimiento. Esta nueva interpretación acerca del dato nos llevó a considerar que el propio silencio (Mazzei, 2003) irrumpiera en la investigación como otro tipo de agente más que pudiera influir en el estudio.

Lo cartográfico tal y como sugiere Braidotti (2018), se convierte en un 
objeto discursivo que favorece el intercambio dialógico. Es en la conversación originada a partir de la producción artística donde surge la posibilidad de que se establezcan nuevos ensamblajes nómadas, donde lo humano y no humano, lo material y lo simbólico se enredan. Sin embargo, como los significados que encierra el lenguaje y los discursos parecen estar siempre en conflicto, ser móviles y contradictorios, existen brechas necesariamente entre la realidad, la experiencia y el comportamiento (Denzin, 2014). $\mathrm{Ni}$ el lenguaje ni el discurso parecen ser fiel reflejo de lo experimentado (Mazzei, 2009). Por todo ello, partiendo de la lectura de la autora St. Pierre (2011a) hemos pasado a considerar al sujeto a modo de "provocateur", tal y como ella denomina al participante en la investigación; no tanto en el sentido de objetos de conocimiento, sino más bien como líneas de fuga capaz de establecernos en otros lugares, a crear distintas conexiones y poder hacernos preguntas que no nos habíamos planteado previamente. No se trata de negar su importancia o su presencia en el texto, sino de utilizar las voces que emergen a partir sus relatos como la excusa que permita repensar la teoría. Esta manera de entender al participante se alinea con un posicionamiento post-cualitativo durante la investigación, alejada de una interpretación humanista del sujeto (St. Pierre, 2000), soberano, lucido, transparente, racional, coherente o unificado, y entendiendo sus voces a modo de "datos" junto a los que pensar. Tal y como apunta St. Pierre (2009) la voz "is part of the humanist discursive...formation poststructuralism works against" (p. 221). Ninguna conversación transcrita puede hablar por sí misma, sus significados no son transparentes sino más bien resultado de una construcción de sus sentidos.

El proceso de análisis de los datos construidos a través de nuestros intercambios y mediados por el proceso de elaboración cartográfica, nos reclamaba estar cerca de todas esas evidencias, pensar con ellas, escuchando los audios, leyendo las transcripciones o las notas de campo, volviendo a ver las producciones audiovisuales o revisando una y otra vez sus relatos visuales. Pero, además, el proceso de análisis también nos ha llevado a tener que leer, pensar, escribir y vivir junto a la teoría (St. Pierre, 2017), mientras recordábamos las conversaciones entre las personas que hemos participado de la investigación o en los intercambios que se originaron con las maestras. Escribir implicaba tener que pensar con los conceptos, lo que suponía leer y dialogar con autores como Deleuze y Guattari, Butler o Foucault hasta el punto de Ilegar a considerar los propios datos como irrelevantes como sugiere St. Pierre (2017), porque 
investigar en definitiva supone "writing and thinking and laying out of the field of the text, moving" (p. 4).

De alguna manera suponía una tentativa a leer los datos a través de las múltiples perspectivas que aporta la teoría. Esta clase de posiciones llevan consigo la necesidad de volver a significar la investigación educativa, colocando los conceptos como el medio que reoriente nuestro pensamiento, deshaciendo los binarismos como el de teoría y práctica, y abriendo la indagación hacia nuevas posibilidades (Taguchi y St. Pierre, 2017). Bajo esta lógica post-cualitativa, la intención no es la de intentar develar significados sino más bien producir sentidos a partir de los datos de la investigación. En el proceso del análisis hemos perseguido que la propia teoría contribuyese a extender el pensamiento de los datos construidos. El propósito es el de abrirse a la posibilidad que ofrecen los conceptos para construir nuevos pensamientos sobre lo que ocurre, más que construir significados e interpretaciones sobre ello (Mazzei, 2013). En este sentido, Deleuze nos habla del concepto como un centro de vibraciones (Deleuze y Guattari, 1993), que no se corresponde con la realidad pero que permite que oigamos con ella. No se trataba por tanto de pensar sobre las cartografías sino más bien a partir de ellas.

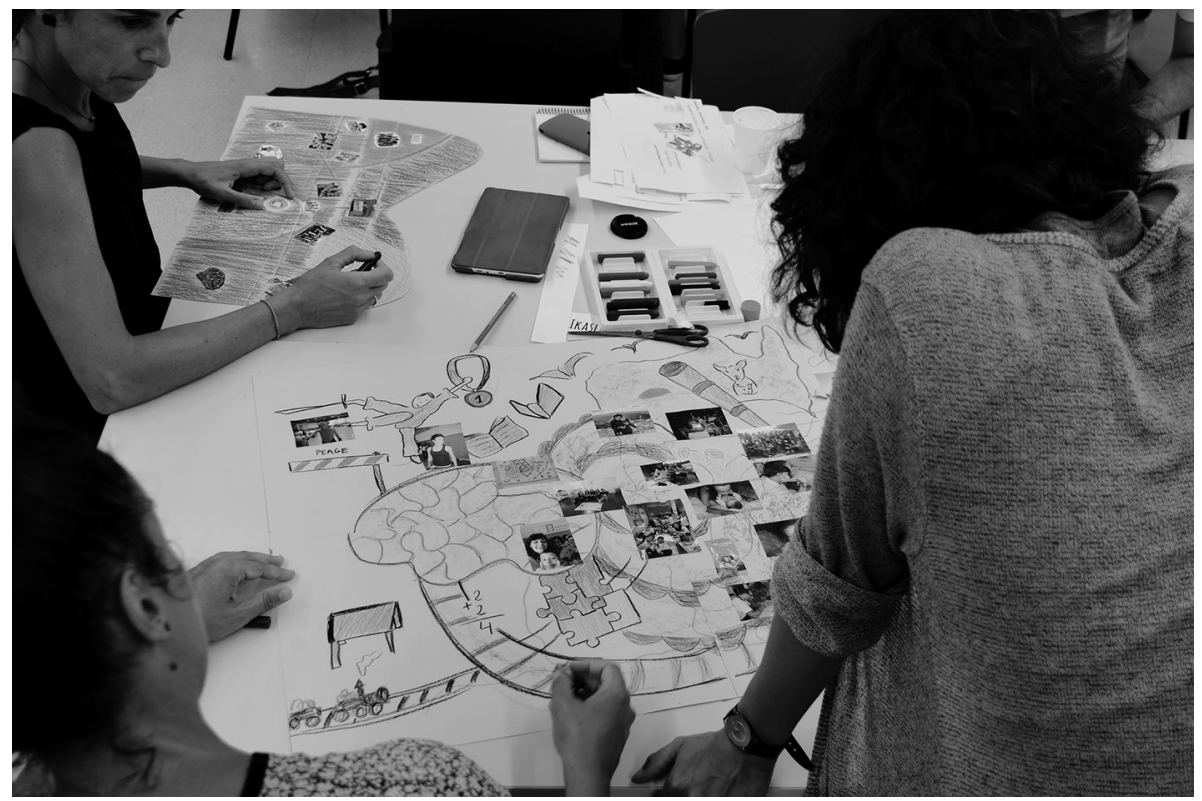

Figura 2. Segunda sesión de trabajo donde se desarrollaron las cartografías en torno a la pregunta cómo aprendo. 


\section{Fragmentos cartográficos del aprendizaje del profesorado. Pensando a partir de los tránsitos}

\section{Fragmento 1. Líneas de fuga: De la obediencia a la propuesta}

Los territorios que encierran las cartografías pueden interpretarse a modo de espacio vivido, tal y como Guattari y Rolnik (2006) lo plantean. Como un "sinónimo de apropiación, de subjetivación encerrada en sí misma" (p. 372). De hecho, "todo agenciamiento es en primer lugar territorial. La primera regla concreta de los agenciamientos es descubrir la territorialidad que engloban" (Deleuze y Guattari, 2004:513). En el camino por explorar las nuevas geografías que encierran los espacios estéticos originados a partir de las cartografías docentes, nos encontramos lógicas de aprendizaje en muchas de las ocasiones contrapuestas. Por un lado, aquellas originadas dentro de las esferas institucionales donde se desarrollan profesionalmente las maestras participantes, y por el otro, las que ocurren fuera de esos límites.

El tipo de aprendizaje dentro del territorio institucional es vivido por las participantes desvinculado de su verdadera práctica diaria. Impulsado verticalmente por sus consejos de dirección bajo un sentido cortoplacista. Siempre con motivaciones al margen de las necesidades que realmente demandan satisfacer sus docentes; pero en lógica, con el contexto de desarrollo profesional que favorece la escuela contemporánea, gestionada bajo una perspectiva racionalista de reducción del gasto, de búsqueda de la eficiencia y de competencia por los "clientes". Esta situación ha derivado en que la profesionalización docente haya llegado a su fin, tal y como asevera el autor Ball (2005). Los intentos por redefinir el profesionalismo dentro de una estructura racional-técnica carecen de sentido, en la medida en que su significado se reduce a la obediencia de las reglas externas y a una forma de rendimiento donde todo se limita a cubrir con los criterios de calidad impuestos. Sin embargo, lo mismo ocurre con el intento por definirla como una práctica ético-cultural, debido entre otros aspectos a las fuerzas que precarizan las condiciones laborales del profesorado y limitan la construcción de sus identidades profesionales. Unas identidades calificadas como post-profesionales, en apariencia muy poderosas pero también muy frágiles, y en determinados momentos, incluso en insostenibles (Ball, 2003).

$\mathrm{Al}$ margen de esta clase de sentidos que adquiere el aprendizaje del 
profesorado dentro de los límites institucionales, los mapas dibujan líneas que intentan salir de dichos espacios y de las lógicas que manejan. Dentro de los relatos visuales de las maestras conviven otros sistemas que no siguen necesariamente dichas formas organizacionales. Encontramos cómo, dentro del territorio -allí donde surge el aprender de las maestras-, existen distintas formas de participación relacionadas a comunidades de aprendizaje, redes u otros sistemas con los que se mantienen vínculos afectivos o de interés y donde emergen necesidades compartidas. Las maestras, al participar o incluso al construir estos nuevos espacios de aprendizaje crean nuevas líneas de fuga (Deleuze y Guattari, 2004) con las que poder desmarcarse de las lógicas de aprendizaje neoliberales, siempre movidas bajo la búsqueda de resultados, y donde su deseo queda necesariamente excluido. Nuestras participantes señalan querer huir de la sectarización del conocimiento que promueven sus escuelas, poco permeables a favorecer otra clase de relaciones entre la comunidad y ellas mismas. La búsqueda de alternativas persigue precisamente satisfacer las necesidades formativas negadas por sus organizaciones escolares en su desarrollo profesional dentro de ellas.

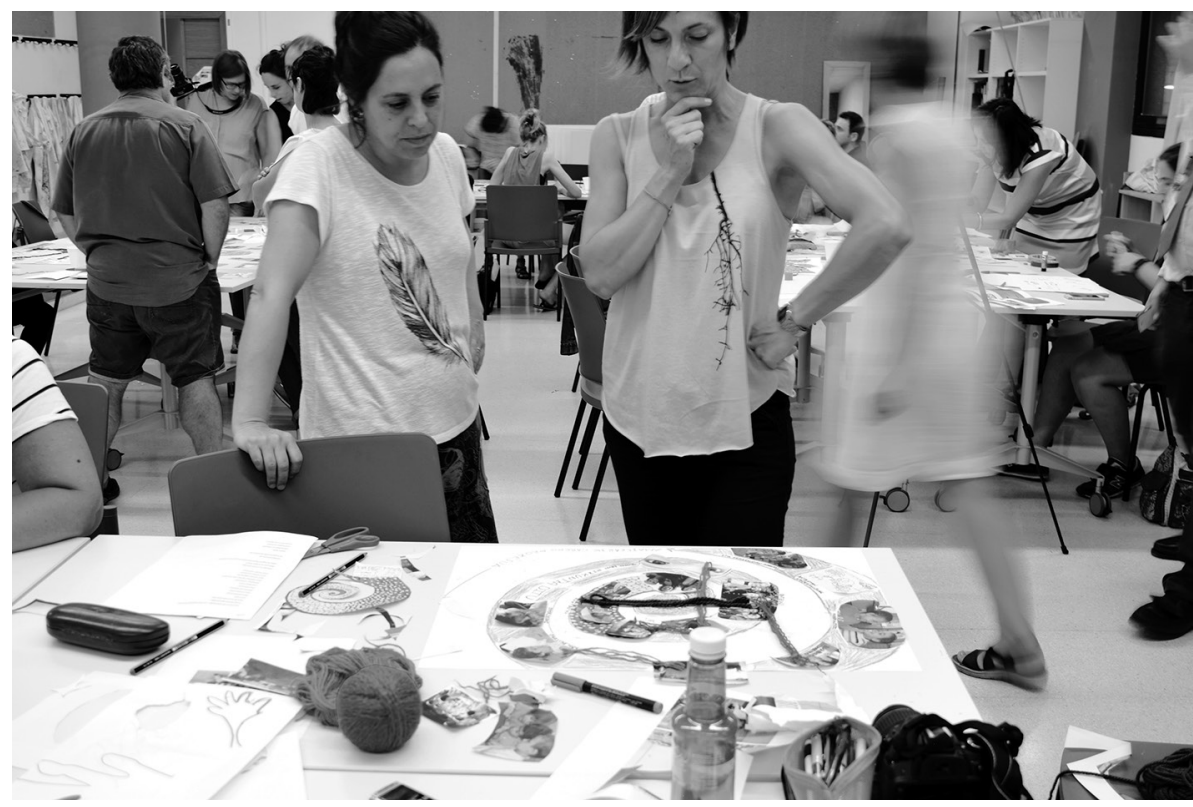

Figura 3. La cartografía como objeto discursivo que permite el diálogo entre la investigadora y la maestra participante. 


\section{Fragmento 2. Re-territorializaciones: Del consumo de aprendizaje al aprendizaje vivido}

Sugerían Guattari y Rolnik (2006) que es en la lucha por la apropiación donde el territorio puede desterritorializarse; es decir, puede abrirse y desarrollar líneas de fuga que lleven a recomponer un territorio que persigue una nueva reterritorialización. Con el propósito de crear esa línea de fuga creadora, la composición de un espacio liso y el movimiento de los individuos bajo ese nuevo espacio, las cartografías de las maestras trazaban las circunstancias bajo las que se origina el aprendizaje significativo durante sus experiencias personales. Durante nuestros diálogos fueron muchas las ocasiones en las que conversamos sobre las circunstancias en las que confesaban convertirse en consumidoras de cursos o píldoras formativas con las que poder satisfacer las demandas generalmente originadas a partir de su contexto institucional. El requerimiento de sumergirse en una suerte de formación continuada, les estaba convirtiendo cautivas de una cultura profesional para individuos programados. Es por este motivo que la relevancia que atribuían a los paquetes de formación diseñados desde las organizaciones a las que pertenecían siempre ha sido limitada. Uno de los motivos por los que esta clase de aprendizaje estaba originando un bajo impacto en su práctica real dentro de las aulas.

Por el contrario, las vías de acceso a la mejora profesional estaban siendo facilitadas por muchas de las redes, en la mayor parte informales, a las que se unían de manera voluntaria. En dichos espacios, donde las maestras dan salida a sus necesidades de formación, encontramos que el aprender adquiere otros sentidos. Ya no se trata de un tipo de aprendizaje basado en el consumo de conocimiento, parcial o totalmente ajeno a sus realidades; sino más bien, un aprendizaje que parte de la propia experiencia personal. La compartición y la reflexión entre iguales sobre la experiencia vivida, parece convertirse en el verdadero motor de cambio de sus identidades y prácticas como maestras. Una dimensión personal, que por el contrario no adquiere ninguna de las otras acciones de formación en las que participan normalmente.

Tomar parte en espacios donde la propia voz sea escuchada y atendida nos llevaba a tener que mirar hacia los significantes de sus cartografías donde se subrayaba la relevancia de la afectividad y los cuidados dentro de su experiencia del aprender. Las cartografías de las maestras 
se constituyen como mapas afectivos donde poner en valor la necesidad de tomar parte en comunidades donde sus inquietudes sean escuchadas. Las maestras hablan sobre la relevancia que adquieren estas dimensiones vinculadas al aprendizaje, en el compromiso y el interés que muestran para seguir ligadas a estas nuevas redes para generar conocimiento. Las oportunidades de encontrar palabras a lo que ocurre en su práctica y para construir un nuevo saber unido a su práctica, se relaciona estrechamente a la capacidad de las comunidades a las que se vinculan para cuidar los unos de los otros.

\section{Fragmento 3. Ensamblajes: De formas cerradas de organización a formas auto-reguladas.}

Las representaciones del aprendizaje que emergen de las cartografías nos llevan a pensar en los desplazamientos que están ocurriendo en las formas de organización de las nuevas comunidades a las que se vinculan las maestras. Por su parte, las estructuras institucionales parecen no estar respondiendo adecuadamente a las demandas personales de las maestras. La rigidez de sus organizaciones para favorecer otra clase de tiempos, espacios y temáticas vinculadas a las necesidades reales del profesorado está yendo en contra del propio aprendizaje. Las redes escolares, se caracterizan por su resistencia al cambio, tanto en las formas de organizarse como de dejarse afectar por las transformaciones que experimentan sus comunidades. La homogeneidad de las personas que las integran, limita al profesorado de sus centros. Algo que dificulta la integración de nuevas ideas a las formas de hacer y pensar que están requiriendo sus escuelas con una diversidad de alumnado que cambia rápidamente.

Las distintas formas de relación que comienzan a emerger en los modos de desarrollo del aprendizaje del profesorado pueden leerse mediante la noción del ensamblaje (Deleuze y Guattari, 2004). A través de Deleuze y Guattari (2004) sabemos que la potencia - puissance-, de un nuevo ensamblaje para actuar es su capacidad para afectar, pero también verse afectado; pudiendo conformar unidades emergentes que respetan la heterogeneidad y diferencia de sus componentes y que están destinadas a producir una nueva realidad, por medio de sus múltiples y frecuentemente inesperadas conexiones (Parr, 2010). En este sentido, los relatos visuales de las maestras que participaron en la investigación 
nos llevaron a poder pensar en las diferencias que caracterizan las nuevas comunidades a las que se encuentran relacionadas. Nuestros diálogos junto a ellas nos permiten caracterizar un tipo de red que se define por su fragilidad, al no poseer del apoyo institucional necesario para desarrollar ninguno de sus propósitos. Pero que, sin embargo, parece mostrarse adaptativo y resistente a las demandas cambiantes de sus integrantes. Algo que afianza el compromiso en el tiempo de las personas que participan en su construcción y mantenimiento. Un tipo de vínculo que se ejemplifica en comunidades como ARTikertuz (Aberasturi, Correa, y Guerra, 2016) donde surge una red de personas relacionadas a diferentes ámbitos como la enseñanza, la gestión cultural o la producción artística, y que favorece que integrantes tan heterogéneos acaben por encontrar un deseo común para seguir aprendiendo los unos de los otros.

Estas nuevas comunidades a las que las maestras se vinculan parecen mostrar formas variadas de verse afectadas mutuamente. El autor De Landa (2006a), partiendo de la noción deleuziana del ensamblaje, apunta a que las distintas comunidades o colectividades que interactúan contribuyen a generar conjuntos molares con consecuencias no previstas. Esta clase de influencias, está favoreciendo que el conocimiento que se genera en una de esas comunidades sea transferido a otras, a través de eventos como el de la polinización cruzada (Hargreaves y Fink, 2008), donde diferentes ideas son transferidas entre las distintas comunidades a las que se pertenece; o incluso el brokering (Wenger, 1998) donde se favorece las oportunidades para construir relaciones entre grupos introduciendo elementos de un tipo de práctica en otro.

\section{Conclusiones}

A través de este trabajo hemos intentado mostrar las principales orientaciones que han marcado nuestra investigación relacionada al aprendizaje del profesorado. Involucrarnos en un proyecto conducido a través del paradigma post-materialista nos ha hecho revisar y poner en crisis muchos de nuestros presupuestos acerca de lo que significa la investigación educativa. Sin embargo, participar en este proyecto también nos ha permitido dirigir nuestras lecturas sobre la realidad hacia otros espacios que anticipamos más coherentes, éticos y comprometidos con las circunstancias sociales que nos han tocado vivir. Asumimos que, al optar por 
opciones epistemológicas desvinculadas de las perspectivas humanistas de la investigación cualitativa, estamos dando la opción a que nuevos matices sobre la realidad irrumpan en nuestras investigaciones, creando la oportunidad para que distintas ideas puedan emerger.

Asimismo, entendemos que únicamente trabajando desde las metodologías visuales y basadas en las artes contribuimos a que puedan surgir esas nuevas ideas que otros enfoques de trabajo tanto nos dificultan encontrar. Una cuestión aún más importante cuando nuestro objeto de estudio es el aprendizaje docente, un ámbito tan naturalizado por mucha de la literatura desarrollada hasta el momento. Únicamente mediante el enfoque cartográfico conseguimos seguir añadiendo tonalidades al sentido que las maestras atribuyen a sus experiencias del aprender. Ayudándonos no solo a ubicar los escenarios donde se encuentran aprendiendo en la actualidad, sino también desvelando su valor como fuente de conocimiento y experiencia.

Durante esta contribución, además, hemos intentado construir un nuevo relato sobre algunos de los tránsitos que se están produciendo en las realidades de las maestras que compartieron su tiempo junto a nosotros. Unos tránsitos que nos hablaron sobre cómo las maestras están favoreciendo acciones propositivas que las Ilevan a construir nuevas comunidades donde satisfacer sus necesidades de formación, movidas en parte por su disconformidad respecto al tipo de aprendizaje que se genera desde sus instituciones. Otros tránsitos, pusieron de relieve lo experiencial como fuente de conocimiento y de desarrollo profesional, en contra de las dinámicas institucionales que tienden a reducir el valor de lo personal. Y, por último, el tránsito que nos hablaba de las nuevas formas de organización del profesorado. Nuevos espacios fuera de sus centros escolares que se conforman a través del altruismo, pero con los que las participantes demuestran un fuerte compromiso y el deseo de dejarse afectar por la diversidad de ideas y personas que los conforman.

Por último, nos gustaría señalar que tal y como recoge el título de nuestro proyecto, unos de los fines que nos planteamos en un comienzo encierra la motivación por atender al cambio social que puede derivar de su desarrollo. Algunos de estos cambios quizá se vinculen a las formas en que las instituciones educativas conciben el aprendizaje de su profesorado y todas las derivas que pueda producir a nivel material en la organización de sus centros. Sin embargo, no queremos olvidarnos de los cambios que nuestra participación en esta clase de proyecto también 
ha traído consigo en nuestra propia labor dentro de la formación inicial y permanente del profesorado. Favoreciendo no solamente una oportunidad para seguir pensando sobre algo tan básico para nuestra tarea como es el aprendizaje del profesorado; sino también, para mejorar nuestra práctica docente en las facultades de educación donde desarrollamos nuestro trabajo.

\section{Referencias}

Aberasturi, E., Correa, J. M., y Guerra, R. (2016). ARTikertuz, ¿qué conocimiento generamos a partir de la relación pedagógica entre profesorado?. EARI Educación Artística Revista de Investigación, 7, pp. 19-38. doi: https://doi.org/10.7203/ eari.7.8134

Achilli, E. L. (1996). Práctica docente y diversidad socio-cultural. Rosario: Homo Sapiens.

Ball, S. J. (2003). Profesionalismo, gerencialismo y performatividad. Revista Educación y Pedagogía, 15(36), pp. 18-104.

Ball, S. J. (2005). Profissionalismo, gerencialismo e performatividade. Cadernos de Pesquisa, 35, pp. 539-564.

Barad, K. (1996). Meeting the Universe Halfway: Realism and Social Constructivism Without Contradiction. En L. H. Nelson y J. Nelson (Eds.), Feminism, Science, and the Philosophy of Science (pp. 161-194). Dordrecht: Kluwer Academic Publishers

Barad, K. (2003). Posthumanist Performativity: Toward an Understanding of How Matter Comes to Matter. Signs: Journal of Women in Culture and Society, 28(3), pp. 801-831. doi: 10.1086/345321

Bennett, J. (2010). Vibrant matter: A political ecology of things. Durham, NC: Duke University Press.

Borko, H. (2004). Professional development and teacher learning: Mapping the terrain. Educational Researcher, 33(8), 3-15.

Braidotti, R. (2000). Sujetos nómades. Buenos Aires: Paidós Ibérica.

Braidotti, R. (2006 ). Transpositions: On nomadic ethics. Cambridge: Polity Press.

Braidotti, R. (2018). A Theoretical Framework for the Critical Posthumanities. Theory, Culture \& Society, $O(0)$, pp. 1-13. doi: 10.1177/0263276418771486

Coole, D., y Frost, S. (2010). New Materialisms. Ontology, Agency and Power. Durham: Duke University Press.

Coole, D. H., y Frost, S. (2010). Introducing the new materialisms. En D. H. Coole y S. Frost (Eds.), New Materialisms: Ontology, Agency, and Politics (pp. 1-43). Durham, NC: Duke University Press

De Landa, M. (2006a). Deleuzian Social Ontology and Assemblage Theory. En M. Fuglsang y B. M. Sorensen (Eds.), Deleuze and the Social (pp. 250-267). Edinburgh: Edinburgh University Press

De Landa, M. (2006b). A new philosophy of society: Assemblage theory and social complexity. London, UK: Continuum. 
Cartografías en torno a los tránsitos en el aprender de docentes en educación infantil y primaria

Aingeru Gutiérrez-Cabello Barragán y Estibaliz Aberasturi-Apraiz

Deleuze, G. (1996). Conversaciones: 1972-1990 (J. L. Pardo, Trans. 2 ed.). Valencia: Editorial Pre-textos.

Deleuze, G., y Guattari, D. (1993). ¿Qué es la filosofía? (1 ed.). Barcelona: Anagrama.

Deleuze, G., y Guattari, D. (2004). Mil mesetas. Capitalismo y esquizofrenia (J. Vázquez, Trans.). Valencia: Editorial Pre-textos.

Denzin, N. (2014). Interpretative Guidelines Interpretative Autoethnography (2 ed., pp. 35-48). London: SAGE

Dolphijn, R., y van der Tuin, I. (2012). New Materialism: Interviews \& Cartographies. Ann Arbor, Michigan: Open Humanities Press.

Fox, N. J. (2015). Personal health technologies, micropolitics and resistance: A new materialist analysis. Health, 21(2), 136-153. doi: 10.1177/1363459315590248

Fox, N. J., y Alldred, P. (2015). New materialist social inquiry: designs, methods and the research-assemblage. International Journal of Social Research Methodology, 18(4), pp. 399-414. doi: 10.1080/13645579.2014.921458

Grosz, E. (2010). Feminism, Materialism, and Freedom. En D. Coole y S. Frost (Eds.), New Materialisms. Ontology, Agency and Power (pp. 139-157). Durham: Duke University Press

Guattari, D., y Rolnik, S. (2006). Micropolítica. Cartografías del deseo. Madrid: Traficantes de sueños.

Haraway, D. J. (1991a). Ciencia, cyborgs y mujeres. La reinvención de la naturaleza. Madrid: Ediciones Cátedra.

Haraway, D. J. (1991b). A Cyborg Manifesto: Science, Technology, and Socialist-Feminism in the Late Twentieth Century Simians, Cyborgs, and Women: The Reinvention of Nature (pp. 149-181). New York: Routledge

Hargreaves, A., y Fink, D. (2008). Distributed leadership: democracy or delivery? Journal of Educational Administration, 46(2), pp. 229-240. doi: doi:10.1108/09578230810863280

Harvey, G. (2014). The handbook of contemporary animism. New York: Routledge.

Hird, M. (2004). Feminist Matters: New Materialist Considerations of Sexual Difference. Feminist Theory, 5(2), pp. 223-232. doi: 10.1177/1464700104045411

Latour, B. (2005). Reassembling the social: An introduction to actor-network-theory. Oxford: Oxford University Press.

Mazzei, L. A. (2003). Inhabited Silences: In Pursuit of a Muffled Subtext. Qualitative Inquiry, 9(3), pp.355-368. doi: 10.1177/1077800403009003002

Mazzei, L. A. (2009). An impossibly full voice Voice in Qualitative Inquiry: Challenging Conventional, Interpretative, and Critical Conceptions in Qualitative Research (pp. 45-62). New York: Routledge

Mazzei, L. A. (2013). Materialist mappings of knowing in being: researchers constituted in the production of knowledge. Gender and Education, 25(6), pp.776-785. doi: 10.1080/09540253.2013.824072

McLaren, M. A. (2002). Feminism, Foucault, and Embodied Subjectivity. Albany, NY: State University of New York Press.

Opfer, D. V., y Pedder, D. (2011). Conceptualizing Teacher Professional Learning. Review of Educational Research, 81(3), 276-407. 
Cartografías en torno a los tránsitos en el aprender de docentes en educación infantil y

primaria

Aingeru Gutiérrez-Cabello Barragán y Estibaliz Aberasturi-Apraiz

Parr, A. (2010). The Deleuze Dictionary. Edinburgh: Edinburgh University Press.

Sheridan, S. (2002). Words and Things: Some Feminist Debates on Culture and Materialism. Australian Feminist Studies, 17(37), pp.23-30. doi: 10.1080/08164640220123425

St. Pierre, E. A. (1997). Methodology in the fold and the irruption of transgressive data. International Journal of Qualitative Studies in Education, 10(2), pp. 175-189. doi: 10.1080/095183997237278

St. Pierre, E. A. (2000). Poststructural feminism in education: An overview. International Journal of Qualitative Studies in Education, 13(5), pp. 477-515. doi: 10.1080/09518390050156422

St. Pierre, E. A. (2009). Afterword: Decentering voice in qualitative inquiry En A. Y. Jackson y L. A. Mazzei (Eds.), Voice in qualitative inquiry: challenging conventional, interpretative, and critical conceptions in qualitative research (pp. 221-236). New York Routledge.

St. Pierre, E. A. (2011a). Post qualitative research: The critique and the coming after. En N. K. Denzin y Y. S. Lincoln (Eds.), Sage handbook of qualitative inquiry (4 ed., pp. 611-635). Los Angeles, CA: Sage.

St. Pierre, E. A. (2011b). Post-Qualitative Research: The Critique and the Coming After. En N. K. Denzin y Y. S. Lincoln (Eds.), The SAGE Handbook of Qaulitative Research (pp. 627-644). London: SAGE.

St. Pierre, E. A. (2017). Writing Post Qualitative Inquiry. Qualitative Inquiry, 24 (9), pp. 603-608. doi: 10.1177/1077800417734567

St. Pierre, E. A., Jackson, A. Y., y Mazzei, L. A. (2016). New Empiricisms and New Materialisms. Cultural Studies $\leftrightarrow$ Critical Methodologies, 16(2), 99-110. doi: doi:10.1177/1532708616638694

Taguchi, H. L., y St.Pierre, E. A. (2017). Using Concept as Method in Educational and Social Science Inquiry. Qualitative Inquiry, 23(9), pp. 643-648. doi: $10.1177 / 1077800417732634$

van der Tuin, I., y Dolphijn, R. (2010). The Transversality of New Materialism. Women: A Cultural Review, 21(2), pp. 153-171. doi: 10.1080/09574042.2010.488377

Wenger, E. (1998). Communities of Practice: Learning, Meaning and Identity. Cambridge: Cambridge University Press.

Wenger-Trayner, E., Fenton-O'Creevy, M., Kubiak, C., Hutchinson, S., y Wenger-Trayner, B. (2014). Learning in Landscapes of Practice: Boundaries, identity, and knowledgeability in practice-based learning. (E. Wenger-Trayner, M. Fenton-O'Creevy, C. Kubiak, S. Hutchinson, \& B. Wenger-Trayner, Eds.). Abingdon: Routledge. Recuperado de http://www.routledge.com/books/details/9781138022195/

\section{Agradecimientos}

Esta investigación ha sido desarrollada dentro del proyecto de investigación I+D+I coordinado APREN-DO: Cómo aprenden los docentes: Im- 
Cartografías en torno a los tránsitos en el aprender de docentes en educación infantil y primaria

Aingeru Gutiérrez-Cabello Barragán y Estibaliz Aberasturi-Apraiz

plicaciones educativas y retos para afrontar el cambio social (EDU201570912-C2-1-R). Financiado por el Ministerio de Ciencia, Innovación y Universidades del Gobierno de España. 